\title{
Understanding Medjugorje Apparitional Experiences: Medical and Parapsychological Perspectives
}

\author{
James Paul Pandarakalam \\ Department of Psychiatry, Hollins Park Hospital, Warrington, UK \\ Email address: \\ James.pandarakalam@nwbh.nhs.uk \\ To cite this article: \\ James Paul Pandarakalam. Understanding Medjugorje Apparitional Experiences: Medical and Parapsychological Perspectives. American \\ Journal of Psychiatry and Neuroscience. Vol. 7, No. 4, 2019, pp. 126-141. doi: 10.11648/j.ajpn.20190704.17
}

Received: November 16, 2019; Accepted: December 5, 2019; Published: December 11, 2019

\begin{abstract}
Background. The continuing apparitional events at Medjugorje in Bosnia offer an opportunity for sceptics to gain fresh insight into an alleged mystical-cum-paranormal phenomenon. Initially, the apparitional experiences occurred in a collective manner ruling out the possibilities of psychological and spiritual artefacts. Ostensibly, according to the percipients, an active apparition - that has inserted itself harmoniously into our three-dimensional world-is manifesting itself at Medjugorje. In this respect, science is hindered by the lack of both theoretical tools and the vocabulary to handle mystical and paranormal events. Apparitional occurrences involve apparitional experience, the apparition and social events. The apparition is beyond the parameters of science and only apparitional experience can be scientifically studied; social events are more important to social sciences and theology. Aim. To test the postulation that visionary experiences involving RSPK, or RSPKlike activity may be instances of apparitions at the physical site and find the results applying this criterion along with other distinguishable features specific to Marian apparitional experiences. To evaluate the different psychological, parapsychological, psychopathological views usually held against true apparitional experiences. Method. Observational and quantitative studies attempted accepting the limitations. Selective survey of the scientific and journalistic literature including previous reviews has been carried out to collect different interpretations which also help to form a framework for an informed conclusion. Results. The voice extinction and sensory disconnection exhibited by the Medjugorje witnesses could probably be explained as a manifestation of psychokinetic-like activity of the apparition. Unlike other generic apparitional experiences reported in the scientific literature on parapsychology, the percipients and the apparition at Medjugorje partake in back and forth communication for extended periods of time. It is obvious that these are not self-generated. Medical studies indicate that there are dual modes of perception proving an inward cum outward apparitional experience. These apparitional experiences have the same pattern as those the officially authenticated Marian apparitions of the past. Additionally, the terrestrial memories revealed to the percipients prove the identity of the apparition as the Mother of Jesus. Apart from the spiritual and religious implications, Medjugorje is thought to be at the forefront of a revolutionary paradigm shift in the field of consciousness studies that may be unprecedented in scope. Psychiatry is currently founded on medical reduction and will have to make many adjustments according to the paradigmatic shifts in cognitive sciences; mental health professionals should be tuned to these ongoing mystical happenings.
\end{abstract}

Keywords: Apparitional Experience, Terrestrial Memories, RSPK-like Activity, Mysticism, Discarnate Survival

\section{Introduction}

It is a scientific assumption that manifestations of the Virgin Mary represent a possible interface between science and religion. Yet, only recently, scientists have made tentative inroads into this hitherto neglected area of research and have begun to scrutinize individual occurrences from a scientific perspective. Reports of Marian apparitions predating the twentieth century have a devotional emphasis that precludes the scientific evaluation of events. It is presently accepted that subconsciously initiated, telepathically endowed idea patterns may explain epidemic appearances of saints in the appropriate cultures. This paper presents a re-evaluation of the Medjugorje events, following from my extant work on apparitional experiences elsewhere [1-3].

The apparitions that have been reported in the twentieth 
century - of which there have been several hundred-have received a different form of attention, and some have been subjected to rigorous scientific analysis. In the second half of the century alone, Mary has been reportedly seen on almost all the continents of the world. According to available evidence, most of these events took the form of intense psychological or human parapsychological experiences. These events might be interpreted as occurring in spatial or temporal clusters, precipitated by presence of a critical set of conditions that lead to the generation of emotional processes that produce apparitions. Such events may be centered on a few focal agents who are capable of-consciously or unconsciously-perceiving apparitions, which are then interpreted within the dominant local religious paradigm [4]. In other words, they could be explained away with a social psi hypothesis.

A full examination of the more credible events of alleged Marian apparitional experiences would provide a theoretical framework for analysing visionary experiences. This, in turn, would enable the scientific community to differentiate between seemingly inexplicable phenomena and explicable but unusual experiences. The Christian religious hierarchy has always maintained a cautious attitude towards the Marian apparitional phenomena. As a result, each has been scrutinized in accordance with the standards applicable at the time; however, the scientific community has always shied away from providing any views on this phenomenon. True apparitional events involve three aspects, the apparition, apparitional experience (AE) of the percipients and social events. While the apparition is beyond the study of scientific parameters, apparitional experiences can be scientifically evaluated.

\section{Medjugorje-Bijakovici}

The first reported Marian apparition at Medjugorje, a small village situated in the heart of western Yugoslavia, took place on June $24^{\text {th }}$, 1981. Initially, the reports of the apparition were met with skepticism, not least from within the ranks of authority, religious and communists alike. However, among the pilgrims who rushed to Medjugorje were scientists who could find no evidence of fakery for personal gain. The author of this work has been following the events ever since. This Bosnian village is not far from the well-known city of Mostar and was a home to 400 families in 1981. Bijakovici is a hamlet adjacent to Medjugorje and some of the apparitional events take place there as well.

The first apparition took place in the late afternoon on June $24^{\text {th }}, 1981$. Mirjana, who was staying with her grandmother during her holidays, visited Ivanka and the two decided to go for a walk. On the way back to the village, Ivanka happened to look toward a hill, and saw the silhouette of the alleged apparition [5]. She wanted to bring it to the attention of her friend, but Mirjana refused to take it seriously. Discouraged by her friend's reaction and unsure of whether she saw something unusual, Ivanka continued to walk with Mirjana back to the village. She did not apparently challenge
Mirjana's dismissal of her experience [5]. After a while, they stopped in front of the house of one of their friends named Milka, who had a sister Marija. Milka asked them to accompany her, as she needed to herd the sheep and bring them home. The friends obliged, and the three of them started to walk back to the fields in front the hill known as Podbrdo, where they saw the apparition with a child in her arms. They were reported to have kept staring in a perplexed state. In the meantime, another friend named Vicka also arrived at the scene. She had previously seen Mirjana and Ivanka and was frightened when they told her that they had seen an apparition.

Vicka was seized by panic, turned around and started to run away. In a few minutes, she reached a stone fence, where she sat frightened, disturbed and crying. Yet, her curiosity was too strong, and she was pondering returning to the site. Then their neighbours, Ivan Dragicevic and Ivan Ivankovic, joined them. However, not long after, Ivan D. started running away and jumping over a stone fence, frightened [6]. In sum, this first experience lasted approximately thirty minutes and involved Ivanka Ivankovic, Mirjana Dragicevic, Viska Ivankovic, Ivan Dragicevic, Ivan Ivankovic and Milka Pavlovic.

On the second day, the group agreed to meet at the place where the alleged apparition occurred. When they arrived at the spot, Ivanka was the first to see the apparition, followed by Vicka and Mirjana. On this occasion, they did not see the child and the experience was preceded by effulgence of bright light. On that day, Vicka had also invited Jackov and Marija. When they all gathered together, the apparition motioned them with her hand to approach her. This frightened them and they ran away from her through the thorn shrubs.

Ivan Ivankovic and Milka Pavlovic, who were present on the first day of apparitional occurrence, never had another AE, even though they repeatedly visited the original apparitional site wishing to see her again. Jackov was apparently moved by the beauty of the apparition and was heard saying to Vicka that the apparition was "as pretty as an actress" [6]. On this occasion, the group was joined by 15 onlookers, who observed them conversing with an invisible person.

On the seventh day after the commencement of the apparitional occurrences, some of the visionaries were taken in a car outside the village to prevent them from going to the apparition hill. However, the visionaries insisted that the car be stopped. As it came to rest, they experienced the apparition at the roadside. The site is called Cerno and a church is built there in the name of St Leopold Mandic. Subsequently, the group reported having AEs on a daily basis in the form of a collective experience involving six regular group members: Ivan, Ivanka, Jackov, Marija, Mirjana and Vicka. These Medjugorje percipients have all reported that they feel misunderstood, criticized and condemned by sceptics. Nonetheless, their AEs have been amply written about.

The Medjugorje apparition did not manifest in the same 
place either, nor to the same chosen individuals. The duration of the $\mathrm{AE}$ was variable as well. Sometimes it lasted for two minutes, while on others it could take up to an hour. It seems that the apparition never manifested at the percipients' will, as the seers reported that even when they prayed, the apparition did not manifest until a little while afterwards, unexpectedly and un-forewarned. In addition, she would sometimes appear only to one member of the group. In short, nobody knew if and when she would appear, and how many would be able to see her. All these observations contradict alternative interpretations based on the hypothesis of autohypnosis and auto-apparition. According to the AE participants at Medjugorje, it stops when the visionary receives the $10^{\text {th }}$ special message, indicating that these events follow a higher logic that precedes human reasoning.

Indeed, at Medjugorje, the visionaries' experiences reportedly continued until they had been given ten special messages each. Mirjana, Ivanka and Jackov have already received theirs, and no longer see daily apparitions [5, 7]. Mirjana received her $10^{\text {th }}$ secret on $25^{\text {th }}$ December 1982 , while Ivanka received hers on May $7^{\text {th }}, 1985$ and Jackov received the final secret on September $12^{\text {th }}, 1998$. These apparitions continue as of today. Marija, Vicka amd Ivan have daily apparitions and Mirjana has one only apparition on the second day of the month. She has an annual apparition on her birthday-March 18th. Ivanka has an annual apparition on $25^{\text {th }}$ June, the anniversary day of the Medjugorje apparitions and our Lady appears to Jackov annually on $25^{\text {th }}$ December.

\section{Hallucinatory Experiences}

AEs are often regarded as being forms of visual hallucinations, as a simple way of dismissing claims made by those who say they have witnessed apparitions. Hallucination is defined a waking sensory experience having no identified external physical stimuli. Visual hallucinations may occur in hysteria, severe affective disorders and schizophrenia, but they are most commonly associated with organic brain conditions [8]. Visual hallucinations appear to the observer in objective space and are three-dimensional, like an apparitional figure. Although hallucinatory experiences are more common in psychopathological states, they have also been reported by individuals of normal mental state.

Pseudo-hallucinations are a special class of psychological phenomenon, manifested as a type of mental image that, although clear and vivid, cannot be fully perceived. They are seen or heard in the state of full consciousness and are located in subjective rather than objective space. Although pseudo-hallucinations are most frequently visual, they are characteristically comprised of complex scenes or fragments of action that are related to a real past event of emotional significance to the individual. Some lonely people would like to have a visible companion in the form of an apparition, while a few profoundly religious people fantasize religious apparitions as a step towards spiritual advancement. These hypnotic hallucinations also occur in the subjective space.
They are usually monochrome and are rarely experienced in colour. The movements of the figures are highly restricted and are very much under the voluntary control. The hallucinatory figure is also within the imaginary capabilities of the individual. Pseudo-hallucination is the most likely phenomenological form to describe the apocalyptic experience of vision [9]. Empirical evidence suggests that even a few hours of social isolation, combined with reduction of sensory stimulation to the lower levels, would produce a state of mental confusion in most healthy individuals. This experience often progresses to organized hallucinations, such as processions of animals and convictions of inner truth [10].

True visual hallucination is most often suggestive of an organic cause. Drug-induced hallucinatory experiences are rarely confined to a single sensory modality. Yet, both true and pseudo hallucinations are unshared experiences, with the exception of extremely rare cases when strong suggestion causes the experience to spread to a second person. Generally, individuals have a narrow vision of hallucinations and this term is wrongly attributed to some of the healthy human experiences. The presence of full insight in the percipient is a feature of pseudo-hallucination comparable to the apparitional experience.

Based on the above view, amateur critics of the Medjugorje events claimed that Ivanka's bereavement was the triggering factor of her visions. Yet, empirical evidence indicates that, when pseudo-hallucinations are experienced by the bereaved, they usually take place in surroundings that are familiar to both the individual subject and to the deceased. Moreover, they are not collectively perceived; rather, one person experiences the hallucination, while others only share the idea and not the hallucinatory experience. Pseudo visual hallucinations and imagery are also mistaken for AEs.

There are no reported true or pseudo-hallucinatory experiences followed by any form of recurrent spontaneous psychokinesis (RSPK) activity. It has been suggested that the form of the hallucination as a psychiatric symptom has much greater diagnostic value than the content [9], whereas the content is claimed to have more research value for parapsychological research [11]. Just as there are pseudohallucinatory experiences, there are also pseudo AEs. For instance, atmospheric apparitional experiences due to retrocognitive memory are not the manifestation of a discarnate intelligence at the physical site.

\section{Generic Apparitions}

All supposed paranormal occurrences consist of a nonphysical event and physical and social events. Though Marian apparitions might be thought of as essentially a transcendental phenomenon, the physical events associated with the occurrences are accessible to scientific study. Because the Marian apparitions are passing through the physical barrier, they are bound to have some features characteristic of generic ones. We have to admit that the physics and paraphysics of Marian apparitional sighting are 
incomprehensible to us, as our parapsychological resources do not allow us to explicate them. Hence, it would be incorrect to quantify all aspects of Marian apparitional experiences with the yardstick of generic apparitions.

The graveyard ghost of fiction is usually described as a white, wispy, semi-transparent figure, typically seen at night. In real-life experiences, an apparition is often misunderstood for a living person and is three-dimensional, often showing awareness of the living. Sometimes, it is also capable of uttering a few words and may even be reflected in mirrors. The experience may last for a few minutes. Even though the apparitional figure appears solid, the percipients would not be able to grasp it, and if cornered, it would disappear or pass through a wall or door.

Psychological experiences may be triggered by natural or man-made phenomena. An example of the former is tectonicstrain-induced luminosity, sometimes misunderstood as apparitions. The fundamental question of whether apparitions are subjective fantasies, or whether they reflect objective reality, continues to pervade scientific circles. Based on the assumption that AEs are associated with shifts in consciousness, two explanations have been recently put forward. The first is that certain altered states of consciousness may instigate powerful, objective and physical effects in the environment. The second is that certain fluctuations in the environment may cause dramatic shifts in consciousness. Accordingly, it is hypothesized that an apparition may be the objective result of mind-matter interaction phenomena, or it may be the outcome of a subjective effect caused by external energies. Yet, these views fail to explain apparitions accompanied by controlled RSPK.

Even though many natural explanations for apparitions exist, none fit into natural interpretations. Presently, six theories of apparition dominate the discussion of apparitions in the scientific literature of parapsychology [12], namely Phantasmogenic Theory, Etheric Body Theory, ESP-PK Theory, Retrocognition Theory, Clairvoyance Theory and Telepathy Theory. The first three theories suggest the presence of the apparition at the physical site, whereas the latter three indicate that the apparition is constructed by the percipient.

Phantasmogenic Theory promotes the view that the apparition generates an image of itself in the mind of the percipient, like a projected hologram, which seems to be a phantom. According to Etheric Body Theory, the astral body of the apparition present at the physical site is seen as an apparition, through normal senses, rather than through ESP or PK powers. ESP-PK Theory, on the other hand, promulgates the view that the apparition is present at the physical site. According to this premise, the psychokinetic powers of the apparition and the ESP powers of the witness result in the actual sighting of the apparition. In addition, both paranormal perception and perception through the normal sensory channels of the witness take place. In my view, this theory has great advantage in explaining apparitional occurrence with the accompaniment of observable psychokinetic activity.

Retrocognition Theory suggests that certain apparitions prove only persistence and localization of something that carries traces of small and superficial, probably obsessive fragment of the experiences by a deceased human personality. In other words, an apparition is the result of the percipient's ESP of past events (Psychometric reading). In psychometry, the percipient is offered an object that belonged to the individual about whom the information is sought [13]. In the past, paranormal investigators deemed this to be a real phenomenon [14-16].

Likewise, the impression left by the deceased individual takes the form of visual image, which may lead to the belief that the departed is haunting the house. Stored psychic traces from the past can evoke apparitions, as objects absorb psychic impressions and play them back to psychically sensitive people. In this respect, they are like psychic echoes. In residual haunting, the image will not interact with a living person. The activity and sightings are random, without any underlying consciousness. Place memory and stone tape theory are extensions of psychometric theory of apparitions. The systemic memory theory of Schwartz and Russek [17] could further illuminate this theory of apparition.

According to Clairvoyance Theory, the apparition is created solely by the percipient, i.e., it is a result of one's own clairvoyant impressions. The telepathic theory advocates the view that the apparition occurs only in the mind of the percipient. However, it fails to explain collective and sitespecific apparitions [18].

\section{Psychokinetic Events}

Psi is composed of sensory aspect-extrasensory perception (paranormal cognition -ESP or Psi gamma) and kinetic aspect - psychokinesis (paranormal action - PK or Psi kappa). ESP is passive and receptive and includes real time (telepathy and clairvoyance) and time-displaced phenomena (pre-cognition and retro-cognition). It can also actively seek out or monitor people or events of interest to the percipient. Psychokinesis is projective and active. It is manifested through the influence of mind on external objects or processes without the mediation of known physical energy or forces. PK is further divided into micro-PK, where the target is the output of a random event generator, and macro-PK, manifested as mental influence on macroscopic physical events. RSPK is a form of macro-PK and involves spontaneous physical effects that are inexplicable in terms of known physical energies, which occur repeatedly over a period of time. Generally, psychokinesis from the living is not spontaneous. Telekinesis cannot be created merely by wishing for it to happen. According to Morse (2011), if one attempts to bend a spoon, it is unlikely that this will happen spontaneously [19]. Yet, if the person returns after an hour or so, he/she may discover that the spoon has changed shape [19].

Living and discarnate agents, as well as natural causes, could account for RSPK. Rhine (1957) has promoted an 
explanation that does not assume a discarnate agency in RSPK phenomena [20]. She also proposed that the observer's own psychic forces are instrumental in producing the apparition. It is generally assumed that psychological factors, especially emotion, are involved in RSPK [21-24]. In the case of RSPK, the role of the living agent leads to the buildup of tensions that are released as psychic energy, whereby the surrounding agents interact with physical objects and its energy. Such an accumulation of energy may be converted into familiar forms, mainly kinetic and sonic energy. As objects are kept in place/forced into motion by gravity and inertia, the role of RSPK agent would be to counteract these forces on the object and direct some form of energy onto it. This process can be better understood if the zero-point energy (ZPE) theory is combined with psi-wave theories and the concept of observer participancy. It is postulated that an emotionally charged object that is freed of gravity/inertia may levitate. By interacting with the ZPE, the electromagnetic component of psi waves could bring about such a transient attenuation of the gravity/inertia.

Walker (1974) posited that, for macro-PK to take place, an outside source of energy is required [25]. His view has been backed by other researches of RSPK [26, 27]. This source could be the zero-point energy or another hitherto unknown energy source, if discarnate realm is brought into the equation. ZPE replaces Myers' concept of ether, which is continuous with the metetherial environment [28]. RSPK activities are involuntary and the agents are not consciously aware of inducing them. Just as driving a car requires sensory feedback, PK may be guided by the ESP powers the agents [29]. According to that analogy, RSPK due to living agents are a form of telekinesis (RSTK). In isolated cases, RSPK agents have been reported to elicit the phenomenon at will [24]. In such cases, at least theoretically, the process could become conscious, especially in prolonged events.

Onset of RSPK has been observed to be associated with geomagnetic perturbations. Extant research findings suggest that known physical energies may contribute to or initiate RSPK activity [30-36]. These energies could include ionization radiation, geomagnetic activity, as well as electromagnetic and electrostatic fields. Cohesion of the electromagnetic field of the vacuum could account for the diminished weight of RSPK objects, and this could explain anomalous electromagnetic readings near RSPK objects or areas. Several RSPK agents have shown signs indicating that their brains were subject to sudden electromagnetic discharges in the form of symptoms of complex partial seizure [24]. However, it is unlikely that such a nominal increase in brain electromagnetic activity would be the cause of RSPK.

Persinger and Roll (2001) also postulated that electromagnetic components of mental state can interact with electromagnetic energy in the environment to produce RSPK events [37]. Joines (1975) detected an emission of $146 \mathrm{MHz}$ in an RSPK area [38]. Changes in the underwater currents and electromagnetic fields are thought to be the natural causes of RSPK [39]. However, these recent findings prompt us to revise the origin of RSPK. In this respect, RSPK has become more of a generic term. In fact, some of the reported cases may be only Recurrent Spontaneous Kinesis (RSK). According to Roll (2004), atmospheric changes are observed more commonly in RSPK due to discarnate intelligence [29]. He also recognizes that RSPK activity has great explanatory value in clinical sciences. It is even possible that living RSPK agents may be acting as transducers for discarnate agents.

\section{Intentional RSPK}

Following preliminary analyses of two haunting cases, Roll (2004) opined that the process may be different from that in poltergeist cases due to living agents. He also recognizes that such cases could point towards survival hypothesis ]29]. RSPK may be associated with living and discarnate agents, as well as natural causes. Rhine's hypothesis, as previously noted, has a fundamental weakness - the difficulty of explaining why a significant psychokinetic effect occurs simultaneously with an apparitional experience to certain people who have never produced such an effect before, and who never do so again. Late Karles Osis, who was sceptical about Rhine's explanation, commented that no psychiatrist had reported a hallucination by a patient that could open the windows of a psychiatric ward. Furthermore, manifestations attributable to discarnate agents are controlled, whereas those produced by a living agent are neither deliberately nor even consciously controlled. Apparitional occurrences that involve physical action provide compelling argument for the involvement of an external agency.

Dr Ian Stevenson (1972) has contributed to discussions within the field of RSPK with his attempt to identify the differences between the conduct and powers of living and discarnate intelligence [40]. Roll (2004) too has made a few suggestions [29], so did Alan Gauld and A. D Cornell [41]. Synchronistic RSPK associated with collective apparitional occurrences cannot be explained away as due to living agents. Medjugorje come under the group of collective apparitions and the synchronism in the RSPK activity are clearly observable there.

\section{Apparition at a Physical Site}

Visions that occur before RSPK manifestations take place are likely to be genuine visual apparitions of the discarnate personality manifesting at a physical site. Those that occur after RSPK occurrences, on the other hand, may be explained as a form of secondary elaboration. These observations may be expressed as follows:

Collective visions + Externally controlled secondary RSPK or RSPK-like activity = Likelihood of visual apparition of a discarnate agent at physical site [2].

This can be compared to the identification of a visitor who knocks on the door by looking through the window, or the 
visitor revealing his/her identity by coming to the glass window after knocking on the door. Thus, the above formula has an affinity with everyday experience, which may be expressed as follows:

Visual perception + Controlled manifestation of physical power $=$ Identifiable living person at physical site.

\section{Medical Tests}

The French medical team, Laurentin and Joyeux (1987), reported both normal and altered physiological parameters [42]. The authors concluded that, at the time of the AE, the individual experiencing it is affected by partial and variable disconnection from the outside world. For example, although sensations travel to the brain of the Medjugorje seers in a typical manner, the findings of evoked auditory potential tests and screening tests show that the cerebral cortex does not perceive the transmission of the auditory and visual neuronal stimuli received from the surrounding environment. This indicates a disconnection located somewhere in the cortex, which can be thought of as functional dualism. Medical tests the Medjugorje visionaries have been subjected to at the time of the AE point towards an objective and subjective or non-objective visionary experience [1].

An Italian team confirmed the aforementioned findings in 1985 and carried out a further series of investigations in 1998. These tests were organized by Dr Marco Margenelli and Dr Giorgio Gangliardi and the research was carried out in four sessions [43]). The first phase of the study was carried out on April $22^{\text {nd }}-23^{\text {rd }} 1998$, at the Casa Incontri Cristiani in Capiago Intimiano. On this occasion, Ivan Dragicevic, Marija Pavlovic Lunetti and Vicka Ivankovic were examined. The second study phase was carried out on July $23^{\text {rd }}-24^{\text {th }} 1998$ in Medjugorje and included Mirjana Soldo-Dragicevic, Vicka Ivankovic and Ivanka Elez-Ivankovic.

In the third study phase, only psychodiagnostic test was conducted on Jackov Colo, performed by psychologist Lori Bradvica. The fourth psycho-physiological examination was conducted on Dec $11^{\text {th }}, 1998$ in which only Marija Pavlovic took part. The team took complete case as well as medical history from each of the seers. They also performed MMPI, EPI, and MHQ, along with Tree tests, Person test, Raven Matrices, Rorschach test, and Valsecchi truth and lie detection test. The percipients were subjected to full neurological tests, computerized polygraph (comprising of skin electrical activity, peripheral cardiac capillary and heartbeat activities, and skeletal and diaphragmatic pneumogrhaphy) during the $\mathrm{AE}$, as well as during the mediated hypnotic recall of the same apparitional experiences. Their tests also included Holter's arterial pressure dynamic registration, Holter's electrocardiographic/respiratory dynamic registration, pupillary reflexes and blink tests, video tape and photographic examinations.

The Italian investigations that took place in 1998 demonstrated that, from the onset of their AEs, the percipients did not exhibit any kind of clinical symptoms. They also reported that the seers did not show any pathological symptoms, such as trance interference, dissociation states and loss of insight into their current reality. All individuals showed varying degrees of stressrelated symptoms due to their current position as visionaries that involved exposure to excess internal and exterior stimuli. The psycho-physical investigation were carried out on four states of consciousness, namely waking state, hypnoticallyinduced apparitional mental state, altered state of consciousness at the time of the alleged apparitional period and state of visualization of mental images. The results yielded by these examinations demonstrate that the apparitional phenomenology can be compared to the one from 1985, albeit with somewhat reduced intensity [43].

\section{Distinct Voice Phenomenon}

One of the outstanding objective features of the alleged Medjugorje apparitional occurrence is a distinct vanishing of the voices of the percipients while they converse with the apparition. The French medical team with an impedance meter has undertaken a rigorous examination of the visionaries' distinctive voice activity, distinguished by unmistakable axiomatic articulation without phonation [42]. Their tests revealed a number of significant findings. The instrument's needle showed extensive movements of the seers' larynx muscles while they recited the rosary before the AE. However, as soon as the apparitional episode began and their voices became inaudible, each larynx stopped moving and the needle soon became still. During their conversation with the apparition, the seers' lips moved without phonation. As the voices returned in the middle of the apparition, as the seers started to recite the Lord's Prayer - which, according to the visionaries, had been started by the Virgin - the needle moved again. Articulation without phonation occurred once more during the final phase of the AE, as the visionaries' voices were replaced by silence, although their lips were moving. As the seers began to speak at the end of the AE, the larynx movements resumed, indicating that the vocal extinction experienced at the beginning of the AE was linked to the absence of larynx movement. Although the seers' lips were moving relatively normally, exhalation did not vibrate the vocal cords. Dr Lucia Cappello from Mostar described, "Then the phase of acoustic black out begins while their prayers were acoustically perceivable up to that moment, they cannot be heard therein, despite the fact that the youngsters keep on praying. That is, the acoustic effect of words is lost, even if the word effect is conserved, in that the youngster continues on moving their lips, or make faces according to their feelings of joy or sadness. The only sound that is perceivable in this phase is the lapping of their lips" [44].

In summary, the percipients' voices became inaudible while they were communication with the apparition. Even though all the muscles involved in speech continued to function, the voice box shut off. This is physically 
impossible, as the laryngeal function cannot be physically isolated from the rest of the speech muscles. The seers' larynxes apparently ceased to emit sound during the AE, except for one incident, when, during the AE, the percipients can be heard simultaneously praying, "Who art in Heaven, hallowed be thy name...." When questioned, the visionaries reported that Mary was leading them in the Lord's Prayer and that does not have to be confidential. The video footage of Ivanka's annual apparition on June $25^{\text {th }}, 1988$ in presence of the French theologian Fr Rene Laurentin, is unique and particularly convincing. Ivanka's voice is audible at the commencement and in the middle of the AE, when she prays with the apparition. It is also noteworthy that her voice also becomes suddenly audible when she requests the congregation to kneel down while the apparition blesses them all. For the remainder of the episode, she can be seen to be articulating normally, but her voice becomes extinct. In addition, Ivanka did not seem to be distracted at all by her daughter's crying while she was in the apparitional mental state. However, her motherly affection manifested immediately after the AE, when she took the baby from her husband. This video footage is available on the Internet.

Fr Svetozar Kraljevic has recorded the following details about the voice phenomenon during an interview with Ivanka Ivankovic in February 1983 [45].

"Svetozar: When you talk with Madonna in your visions, we cannot hear you speak.

Ivanka: We speak out loud, the same as now.

Svetozar: Let me put in this way. Do you speak with the Madonna mentally - that is she understands what you think - or do you speak to her in a low voice, a whisper, so we cannot hear you? Or is your conversation miraculousbeyond our power to hear and understand?

Ivanka: I speak with Her normally, the same as I am speaking now. Also, I hear Her voice and words in the normal way, as well as what the others say."

The silencing of voice production reported in Marian apparitional occurrences has not been recorded in the RSPK literature. This was observed in France at Lourdes in 1856, at Fatima in Portugal in 1917, at Beauraing in Belgium in 1932, at Garabandal in Spain from 1961 to 1965, and also at Medjugorje in Bosnia from 1981 to the present. This phenomenon has analogies in the controlled type of RSPK and may be presumed as externally composed superior psychokinetic-like activity with a mystical quality. These phenomena become more readily explicable once a model of controlled RSPK is evolved for use in scientific analysis. Without the application of such a technique, they could be overlooked owing to the plethora of amateur psychiatric terminology applied to them.

Rene Laurentin, the French theologian, who conducted an in-depth study of the eighteen apparitions at Lourdes, confirms the selective inaudibility of Bernadette, the sole visionary there. In historical cases - or which, as we have seen, reporting lacks scientific discipline-discrepancies in the detailed descriptions of events are to be expected. However, the books describing the visions at Fatima unanimously report a different form of selective inaudibility that was noted with regard to the six apparitional experiences that took place there. There were three percipients at Fatima, of whom it was reported: "Lucia sees the Lady, speaks to her and hears her. Jacinta sees the Lady, hears her, but does not address her. Francisco sees the Lady, but neither hears nor speaks to her" [47]. From a parapsychological point of view, this may be termed "internal inaudibility" on the part of the visionaries, as Jacinta and Francisco were silent, while Lucia spoke. Such an internal voice black out from the part of the apparition has been recorded in the La Salette apparitional occurrence that occurred in 1846 [46].

Maria Carreira-one of the witnesses of the events at Fatima-confirmed the external inaudibility of the voices of the visionaries. According to Walsh [47], "when the children started running to the tree, we did that too ... then we started to hear something. It sounded like 'a high frequency voice,' but no one could understand a single word. It was like the sound of bees".

The voice phenomenon has been thoroughly investigated in relation to the current apparitional occurrences at Medjugorje, as previously described. In the collective apparitions at Beauraing, where five percipients were involved, inaudibility was not recorded frequently; however, Father Schellinckx [48], who observed the apparitional experience closely, stated, "Little Gilbert moved her lips. After this I saw her, her head devoutly inclined, lost in the depths of prayer". Voice phenomenon was also identified in the Garabandal apparitions [49].

Three components of voice production are involved in the utterance of the "spoken word"-the voiced sound, resonance and articulation. The basic sound produced by vocal fold vibration is referred to as "voiced sound," or a "buzzy" sound. Voiced sound is amplified and modified by the vocal tract resonators - namely the throat, mouth cavity, and nasal passages - that produce a person's recognizable voice. The tongue sift palate and lips are the vocal tract articulators that modify the voiced sound resulting in recognizable words. "Buzzy sound" has been reported to have been heard in Fatima and Garabandal, as well as by close observers at the Medjugorje apparitional site. Diaphragm is involved in the production of the voiced sound and the recording of the muscle movements of diaphragm showed the same counters as in a person that is speaking. In other words, voiced sound is produced while the visionaries are conversing with the apparition. Articulation is also taking place, albeit without the resonating part. In addition, although the visionaries are recognizing their voice, its amplification is interfered with. The visionaries have reported that, during the $\mathrm{AE}$, they were able to hear their own voices, just as they would in normal verbal communication. Hence, they were surprised that others could not hear them. Video recordings and photos demonstrate that, during certain periods of the $\mathrm{AE}$, a number of the percipients converse with one another and hold different conversations simultaneously.

During verbal communication, we have an auditory control of our voices that, in turn, affects the speech movements, 
including articulation of the lips [50]. This is one of the reasons why the lip movements of deaf and dumb people attempting to speak are different from those of normally speaking persons. In contrast, even though the voices of Medjugorje visionaries are inaudible during their verbal communication with the apparition, their lip movements appear to be as if they have auditory control of their voices. This observation itself rules out manipulation and psychogenic aphonia. Critics of Medjugorje also argued ventriloquism as an alternative explanation. However, ventriloquism is phonation without involving lip movements, whereas the voice phenomenon in question is articulation without phonation. I admit my reluctance to accept such distinctly recognizable acoustic blackouts that have been taking place for thirty-eight odd years as pretension on the part of the visionaries.

\section{Psychokinetic-like Phenomena of a Higher Order}

As discussed in a preceding paragraph, visionary experience with RSPK activity strongly suggest the manifestation of apparition at the physical site. The voice black out is distinctly observable, externally induced and controlled. The present author would like to refer to the controlled voice phenomenon as a Psychokinetic -like phenomenon. In heuristic terms, the selective inaudibility of the voices of the Marian visionaries as observed clearly at Medjugorje is like that of an externally controlled positive psychokinetic- like phenomenon, but it is certainly more than that. In other words, the vanishing of the voices of the percipients of Marian apparitions is an "externally controlled superior Paraphysical-like" phenomenon or a transcendental type of psychokinetic phenomenon.

The collective apparitions at Medjugorje meet the criteria considered earlier, in that controlled paraphysical-like features (external manifestation of apparitional power) have been a significant component of them. The frequently depicted "solar miracle" of Fatima may be an aerobic phenomenon. It might be hypothesised that cascading of superior psychokinetic-like activities (spiritual powers) from the part of the apparition caused local geophysical alterations, from which the light phenomenon ensued. Similar phenomena have been reported in the early periods of the Medjugorje apparitional occurrences.

The persistent voice phenomenon demonstrated by the Medjugorje visionaries, the partial sensory disconnection to the exterior world and the selective sensory disconnection within themselves seem likely to be manifestations of the superior psychokinetic-like/spiritual powers of a mystical nature from the part of the apparition or combined with the PK activities of the percipients, which is evidence of a physical presence at the site. Visions + Selective inaudibility of the voices of percipients and other superior psychokineticlike activities $=$ Strong possibility of Marian Apparition at the physical site.

\section{Two-fold Perceptions}

Theoretically visionary experiences can occur as ordinary sight visions, non-physical objective visions and subjective visions. Ordinary sight visions involve ocular stimuli and physical illumination; object and physical lights are perceived as though appearances are as part of the earthly realm (physically objective). But most often perception of apparitional figure happens without physical illuminations and even in darkness, but objectively and externally (nonphysically objective). Under this scenario, the apparitional figure would be visible to those that it allowed specifically to see it. Subjective visions are perceptions without ocular stimuli in the absence of physical illuminations, and centrally stimulated. Subjective pseudo visions occur in altered states of consciousness due to internal stimuli of the person as in dreams, hallucinations etc (purely subjective) and subjective true visions can rarely occur due to external stimuli independent of the percipient without ocular stimuli and physical illuminations (subjective objective).

On the occurrence of the objective non-physical sighting of an apparitional figure, the psychokinetic-type powers of the apparition effectively illuminate the ocular apparatus of the percipient. What happens is analogous to illuminating someone in darkness by directing a powerful beam from a torch upon them. Furthermore, apparitions have a tendency to discriminate - they may direct their psychokinetic powers to selected persons, excluding those who stand alongside them.

The apparition is capable of illumination and of selectivity. When the apparition is the physical manifestation of the Blessed Virgin Mary, more features that we may term 'blackout phenomena' are identifiable during the paranormal event. The distinctly observable voice black-out of the percipients are described in the preceding paragraphs. As the voice of the apparition is not heard by the witnesses to the events, but is heard by the visionaries, it is accurate to say that the BVM performs a selective acoustic black-out of herself during her manifestations. Of note, there is a partial sensory black out to the external physical world from the part of the percipients. When we consider that the apparition as authentic, there is also an apparent visual black out of the apparition to the witnesses around the percipients- a visual black-out of the heavenly personage. All the four forms of black-out that is acoustic, sensory and visual in nature, in my view, may be outcomes of the psychokinetic-like powers of the apparition. The acoustic and sensory black outs of the percipients have been medically tested while the other two black outs are not testable and are only assumptions.

Both exteroceptive and interoceptive senses are involved in Marian apparitional experiences and result in objective and subjective visions. In the Marian visions at Medjugorje, there is objective-external and subjective -internal perception which is paranormal perception of the apparitional figure. The medical findings support such a dual mode of perception as described below: [42]. 


\subsection{Physical Perception}

1. The convergence of the gaze of the percipients as confirmed by video recording.

2. The simultaneity of the cessation of eyeball movements as established by electro-Oculography.

3. Articulating movements suggestive of conversation with an outside agency.

4. Behaviour and facial expression suggestive of an external reality in front of the Seers.

5. Squinting of the eyes noted particularly during the apparitional experience of Mirjana.

6. The simultaneous raising of the eyes of the percipients and heads as the alleged apparition disappears upwards.

\subsection{Paranormal Perception}

1. The screening test does not violate vision.

2. The normal visual pathways are not used.

3. The evoked auditory potential test proves that during the $\mathrm{AE}$ the auditory pathways are normal.

4. The normal auditory pathways are not used.

There have been also instances of subjective visions alone without objective visions at Medjugorje. An observation suggesting 'subjective-objective' perception is two of the visionaries' reported apparitional experience while they were having operations under anaesthetic. Vicka was undergoing an operation for appendicitis in a Zagreb Hospital in 1984. This happened an hour after the operation while Vicka was still under the influence of anaesthetic. Her carer who escorted Vicka reported: "If I had a video recorder and if I could have recorded the apparitional experience we would have had the final answer for all those who wonder if it is possible or not, for all those who are in doubt". According to Marija, a discrete apparitional occurrence happened to her on December 16, 1988 and took place in the United States at Birmingham, Alabama while the twenty-three-year-old seer was undergoing an abdominal operation to donate one of her kidneys to her brother [51].

\section{The Identity of the Apparition}

While, through her predictions, the apparition at Medjugorje has taken the percipients forward into the future, she has also regressed them in time by revealing her terrestrial memories of events that took place some 2000 years ago. It is widely accepted that a particular genetic combination determines the physical identity of a specific person, while our personal identity is composed of memories. Hence, for those that have witnessed it, the overt remembering of the apparition presents a sequence of earthly experiences that validate her existence, continuation and unique identity.

The apparition has revealed her personal earthly memories in detail to some of the visionaries at Medjugorje [52]. One of them, Vicka, has kept a written record of the recollections revealed to her. These were conveyed in verbal and nonverbal language, both of which were Vicka's instruments for describing the apparition's life history as well as her memories. The narratives Vicka shared provided evidence of the apparition's identity as the mother of Jesus Christ and therefore constituted a reaffirmation of the divine incarnation. With the exception of Mirjana, the apparition promulgated details of her terrestrial life to all other visionaries, albeit with some distinct variations in the mode of presentation.

Ivan was the first visionary to receive this particular privilege. He later related that the Holy Virgin honoured him by revealing information about her terrestrial experience on two occasions, 22 December 1982 and 7 January 1983. On the latter date, he recalled that she had begun to tell her life story to all remaining visionaries present, apart from Mirjana. According to their testimonies, she ceased to relate her life story to Jackov first. Her presentation of earthly memories to Marija came to an end next, as she last received a message on 17 July 1983, when only brief information was conveyed. The distinctive feature of these particular accounts is that Vicka has been vouchsafed a longer exposition of terrestrial memories than the others have. Thus, Vicka's reported eight visits to Holy lands may be inspired by the earthly memories of Our Lady.

All the visionaries who heard some elements of her life history - in this particular case, Ivan was the exceptionwere enjoined to remember the details and even to record them, allowing them to subsequently convey to others what they had been told. They were also given specific instructions regarding their future actions. Although Ivan was not specifically encouraged to record what he was told, he elected to write down some of the more important things he learned, as he was keen to document them for himself. Although all others kept a record of the information received, Ivanka's mode of preserving of the apparition's life story is in a distinctive format. She alone was given a special coded script, which she used to keep notes.

As explained, Vicka has produced the most detailed account of the earthly memories of the apparition. The terrestrial memories that were recounted to her reveal the vision to be an apparition with a mind, as distinct from a spontaneous appearance that would typically lack consciousness. It is also noteworthy that the memories are quintessentially Jewish in nature. The earthly experiences the apparition of Medjugorje conveyed to this group may thus be regarded as confirming the events there as an authentic Marian apparition. Needless to say, this rests on the premise that the reliability of the memories and trustworthiness of the visionaries is accepted. The visionaries also concurred that the apparition sometimes prayed in Aramaic language over the crowds. The terrestrial memories of the apparition, probably with verifiable details, point towards a Biblical apparition at Medjugorje. It is also true that, at present, our knowledge of the life of the BVM is far too limited to allow us to validate these memories.

\section{Not Self-generated}

The Super-psi hypothesis may not be particularly relevant 
in the discussion of collective apparitional events. Super-ESP has been considered by non-survivalists to be an alternative explanation for apparitional phenomena, and Super-PK does not seem to have been brought into the debate. Its notable absence probably stems from the fact that the coexistence of apparitional experience with RSPK has not received much attention in the course of considering authenticity. Even in a recent publication on anomalous happenings, physical phenomena received scant attention [53].

In the case of Marian apparitional experiences, the intrinsic ESP and PK are of a distinctive and extraordinary nature. It is assumed that only the ESP powers of the percipients, enhanced by the PK-type powers of the apparition, are involved. However, according to the Super-psi hypothesis, some form of refined psychokinetic power on the part of the percipients would be intrinsic to the apparitional sighting. Refined PK requires intense ESP monitoring of the resultant activities [54]. Yet, the Super-psi hypothesis fails to hold true when we consider that up to six percipients are simultaneously involved in the Medjugorje visionary experiences. The voice blackout is hypothesised as an RSPKtype feature that, as I have argued elsewhere, is controlled by the apparition. Parapsychologists are accustomed only to observing and reporting on RSPK action on physical objects. Sound production is a physical phenomenon and the disappearance of the voices of the Marian visionaries is another externally generated and controlled PK-type phenomenon. I posit that it is, in fact, a transcendental kind of psychokinetic activity.

For the Super-psi hypothesis from the living to be true, one has to conjecture that the Super-psi of the visionaries generates an identical auto-apparition. In addition, the ESP powers of the six percipients must constantly and consistently monitor the voice phenomenon, without failure. To achieve that level of synchronicity, an extraordinary kind of insulation would be required, whereby a multi-process Super-psi is activated without any invasion into the mental activity of the witnesses over a period of several years. Having visited the Medjugorje apparitional site on several occasions, I contend that there is no possibility of such an orchestrated PK-activity eventuating.

A simple simile may help to clarify this claim. A coordinated Super ESP-PK activity is comparable to driving a motor car while receiving feedback from both the vehicle and the surrounding environment [54]. In order to align this example with the experience of the six visionaries, let us consider a hypothetical driving scenario in which six cars move alongside each other while their untrained young drivers are focused on six different points. The cars will inevitably collide. If Super-ESP is posited as the regulator of the psychokinetic activity, at Medjugorje, there would be six regulators without a supervisor. The apparitions they perceive would thus have to be robotic auto-apparitions without a purpose. Quite apart from that impossibility, we would need to determine a motive for the percipients. Even if we suppose that a multi-process Super-psi of the percipients is implicated in the group sighting of an auto-apparition, this still does not explain the type of agency that coordinated all the externally controlled and collective Super-psi. If an apparition of a higher order is excluded from the equation, we are left with what we may designate a psi-orchestra, playing without a conductor.

To make their theory more tenable, the proponents of Super-psi need to convince others of the identity of the master trainer, who would have had to educate the Medjugorje visionaries, enabling them to develop high psi faculties. In reality, having been brought up in a predominantly atheist culture, they were not even aware of human abilities such as these. Their celestial experiences came spontaneously, and neither of them demonstrated any unusual psychic faculties in non-apparitional situations. An avid supporter of the Super-psi theory would have to attribute superhuman powers to the visionaries. My own contention is that, whenever collective and controlled RSPK-type activity is involved, as in the case of Marian apparitions, even the presence of Super-psi does not preclude an apparitional manifestation at the physical site.

Accepting the ESP-PK hypothesis of apparitions as one of the criteria, with all its fragilities [2], one might conjecture that an inter-actionist psi is involved in the sighting of Mary, as well as in non-verbal cognitive exchanges between the apparition and the percipients. There is no evidence to suggest that the psi or Super-psi of the percipients controls the apparitional events. On the other hand, such powers may become instrumental in the visionary experiences. The selection of the percipients over a period of 38 years, the abundance of apparitions, the unique and unparalleled voice phenomenon, the distinctly different presentation of the terrestrial memories to the group of percipients, the variable predictions of future events to different percipients, and the visible sign predicted a long time in advance-all these argue against the Super-psi hypothesis of living agents.

Denial of the existence of Super-psi does not particularly favour discarnate existence and may even be self-defeating when it comes to the notion of survival [55]. It is possible that Super-psi is a requirement for survival, as the ordinary psi demonstrable in the laboratory may be insufficient to sustain discarnate survival. I share the view put forth by Beichler (2008), who regards the afterlife and Super-psi as equivalent and interchangeable, as the source for Super-psi is identical to that which survives physical extinction [56].

Proving the existence of a non-physical component that is in some kind of symbiosis with the brain itself may offer indirect proof of discarnate existence. If we were able to identify an organ that allows someone to fly, this would indicate that the organism in which this power manifested was capable of some form of air travel, even though the organism has never been independently observed in flight. A non-biological component (Super-psi) analogous to the hypothetical organ facilitating flight may be an indirect indication of survival after physical extinction. All the types of evidence postulated in favour of discarnate survival simultaneously confirm existence of a non-biological component that operates in association with the brain, and 
vice versa. Different low- and high-energy bodies have been hypothesised to exist beyond the physical body, which is analogous to the outer covering of an onion ring, the central core being the celestial body. If Super-psi exists, it may be a faculty of the celestial body - the Super-shin (spiritual body). The following observations provide counter claims to the Super psi hypothesis from living agents:

1. Visionaries did not have any self-training or hetero training aimed at sharpening their psi faculties.

2. Visionaries were unaware of any unusual psychic faculties inherent in themselves and lacked any knowledge of its mere concept.

3. They were not particularly very prayerful or engaged in any form of meditative practices.

4. All experiences were spontaneous.

5. Visions occurred collectively and in a highly controlled manner.

6. Percipient selectivity over a period of 31 years (the number of visionaries remains the constant).

7. Apparition is invisible to the witnesses.

8. Self-induced psi faculties are bound to vary in quality and quantity and are expressed to varying degrees among individuals. On the other hand, the apparent experiences of six Medjugorje visionaries are more or less equal in both quality and quantity.

9. Self-generated psychical abilities are also variable on different occasions, depending upon the mental state of the percipients. In contrast, the experiences of Medjugorje visionaries have been consistent over time.

10. Each visionary reported cessation of the experiences upon receiving ten special messages. This specificity cannot be explained when these experiences are assumed to be self-generated.

11. The apparition presents itself simultaneously at different sites at the same time.

12. Visionaries have not demonstrated any unusual psychic abilities in non-apparitional situations even though pilgrims expect such powers from them.

13. Visionaries note identical features when describing the apparition.

14. At the onset of these visions, there were no specific emotional precipitating factors, which would be necessary if the experience involved Super-psi.

15. Super-psi from the living would be a sporadic event, whereas Medjugorje phenomenon follows a regular pattern with its own logic.

16. The percipients claim to see an apparition with a special purpose.

17. The behaviours of the percipients and the witnesses were modified by the apparitional occurrences far beyond the expectation of a Super-psi-mediated phenomenon.

\section{Not Mediumship}

Mediumship is another alternative interpretation of the events that transpired at Medjugorje suggested by amateur parapsychologists. Yet, unlike mediums, Medjugorje percipients never initiated their extraordinary experiences, as these were imposed on them instead. In fact, Ivan Dragicevic was a reluctant visionary. Significantly, the apparitional experience never occurred upon request of the visionaries or the witnesses, and the seers were beyond the ordinary human logic of behaviour during the events. According to the percipients, 6:40 PM was the time set by the apparition for daily apparitional experience. It seems that the apparitional experiences occurred when visionaries were deemed ready and sometimes took place unexpectedly.

The three varieties of mediumship_-mental, trance and physical-are often intertwined. Channelling may relate to receiving some form of communication from such a oncehuman source as these. It does not necessarily involve a discarnate entity, as it may also emanate from any nonphysical intelligence [57]. More energy transmission is claimed to come from channels than from structured knowledge. During such experiences, neither mental and trance medium nor channel perceives an objective reality before them. In this respect, they differ significantly from the Medjugorje visionaries, who apparently encountered an objective reality.

Unlike the mental mediums, at Medjugorje, six visionaries make a collective, reciprocal-telepathic communication either singularly or simultaneously with a spiritual reality. This clearly differs from the generic mental mediumship. Mother Mary represents a higher spiritual dimension encompassing richer realities, whereas the communicators of mediumistic messages originate from a less spiritually advanced realm. Mediumistic communicators also tend to be copious in their renderings. On the other hand, in Marian apparitions, communications are rationed and are focussed on how to bypass purgatory and avoid eternal damnation.

Medical studies have shown that the Medjugorje visionaries were only partially cut off from the sensory world, and there is no evidence to suggest the occurrence of autohypnosis in relation to their experiences. In addition, in the Medjugorje visions, there is no evidence of any intense concentration before the visionary experience. Moreover, the Medjugorje seers emerge from their apparitional experiences precipitately, whereas hypnosis subjects come out the trance state slowly. Trance mediums are also unable to recount their experiences during the trance state, whereas the percipients of Marian apparitions are capable of recollecting their celestial experiences and the conversations.

As previously noted, these visionary experiences were never initiated by the visionaries. A noteworthy observation emerging from Italian psychological tests [43] was that a hypnotically induced apparitional mental state in the visionaries did not cause the same phenomenology as their spontaneous apparitional experiences did, suggesting that the latter are not mental states of hypnotic trance.

Physical mediums act as a reservoir of ectoplasm, whereby discarnate spirit is unable to communicate with the living without the aid of co-operating mediums and an ectoplasmic voice box. Materialised robotic spiritual manifestations 
through the physical medium present different features even from the generic apparitions of discarnate spirits, who seldom speak. They are more akin to materialised bodily forms, without any of the qualities of an active apparition. While only parts of the body are sometimes materialised, the bodily form is visible to all the sitters of the séance and has been photographed on a few occasions [58]). Medjugorje apparition is distinctly different from such materialised forms.

The heavenly apparition is reported as being clear and vivid in various visual aspects, such as colour, texture of skin and clothing. The apparition was also viewed at different distances, depending on the occasion. The brightness of the figure was reported as being independent of external light sources, as it did not fade or become brighter when light was limited. The visionaries also reported that the apparition would obscure the background, making everything in front of the visionaries disappear. If a hand is placed on the apparition, a normal physical touch is reported. According to the visionaries, the experience is an interactive one.

Most importantly, the apparition is visible only to the chosen ones and was never reliably photographed. Unlike mediumship, Medjugorje apparitional experiences clearly entail most of the attributes of mystical phenomenon. Physical mediums require years of training, whereas the Medjugorje visionary experiences were spontaneous ones. Psychical researcher Hamlin Garland reported on sitting silently in the darkened séance circle for as long as four hours before any sensations developed. Similarly, medium Sophia Williams shared that she sat quietly each day for four years to learn the art of relaxation and complete detachment before her own mediumship really began to develop [59].

One has to jump off several fences to arrive at the Marian apparitional views of Medjugorje. If a "paranormal fraud" in the name of Blessed Mother is brought to the equation; even the best parapsychologist currently has no way of recognizing the identity of discarnate spirits unless they prove it by themselves. One way of solving the riddle is by applying the Biblical test- a tree is known by its fruits. "For a good tree does not bear bad fruit, nor does a bad tree bear good fruit. For every tree is known by its own fruit. For men do not gather figs from thorns, nor do they gather grapes from a bramble bush. A good man out of the good treasure of his heart brings forth good; and an evil man out of the evil treasure of his heart brings forth evil. For out of the abundance of the heart his mouth speaks." Luke 6: 43-45. We cannot do without theological aid when we attempt to study paranormal cum mystical phenomenon.

\section{Discussion}

According to the sceptics, hallucinations and psychological disturbances emanating from belief, expectancy and possibly fraud are prime causal candidates for Marian apparitions. Undoubtedly imitation and fraud deliberate and/or subconscious - may be factors in specific instances. Nevertheless, the fraud theory in relation to the visions of the Blessed Virgin Mary at Medjugorje has been convincingly challenged [6]. Had there been fraudulent phenomena, the young visionary group would have dispersed under the suppression of the communist regime and the chaos of the Balkan war. Two of them, Ivan and Jackov, underwent their compulsory military training in the former Yugoslavia, but their apparitional experiences continued uninterrupted except for a few days in the initial period. Their military commanders were aware of their experiences and were unable either to terminate them or to discredit them. Paul Cunningham, who has produced publications on the transpersonal perspective of Medjugorje, discussing its implications for consciousness studies, rules out any form of outright fraud [60].

Incontrovertibly, there are no true or pseudo-hallucinatory instances in which the voices of the percipients vanish. Those at Medjugorje do not see a hallucinatory figure, but a talking apparition in objective space with a specific purpose. The apparitions are three-dimensional and the figure before them is active. The apparition engages them, and their encounters are manifestly not mechanical. Even though she does not belong to their space-time dimension, she has apparently infiltrated herself harmoniously into our three-dimensional world. Another negative view of that of theologians who have expressed concern that the events are an outcome of diabolical power. The present author has argued against diabolical and iniquitous spiritistic interpretations elsewhere [3].

The dual modes of perception suggested as a result of medical observations approximately fit the ESP-PK theory of apparition. This hypothesis has not been convincingly contested. It does not, admittedly, accommodate all the physical manifestations at Medjugorje, but it has some explanatory value. It may help to bring the events there into the realm of the parapsychologist.

According to the ESP-PK theory, the psychokinetic powers of the apparition and the ESP powers of the seers bring about the sighting of the apparition, who becomes present at the physical site. The ESP powers of the percipients are activated by the psychokinetic activity of the apparition [12]. The hypothesis may perhaps be modified to encompass the idea that not only the ESP powers but also the psychokinetic abilities are intensified by the apparition. The apparition is capable of interacting psychically with physical reality, resulting in its image being perceived by the seers through their normal sensory channels. At the same time, the ESP powers of the percipient are activated, and the self-images emanating from the apparition are perceivable through ESP. This means that there are dual modes of perception. The apparition is seen physically as well as subjectively.

Critics of the ESP-PK hypothesis may argue that this is essentially a two-pronged approach, and that it is hard to make sense of either aspect because many questions are as yet unanswered. This response by those who are sceptical about discarnate existence and transcendental realities is perhaps inevitable. It is arguable that if sensory perception is taking place as the outcome of a physical simulacrum of the 
apparition, one might expect other persons present at the scene to see it. That does not happen - witnesses are unable to see the apparition. That leads us to conclude that the vision itself is selective and controls the process. It should be noted that even generic apparitional experiences are sometimes selective.

As indicated earlier, the Medjugorje apparition is capable of instigating what may be termed a visual black-out through her own psychokinetic powers. Opponents of the ESP-PK theory may dispute my regard of the blockage of voice production as an outcome of $\mathrm{PK}$ emanation from the apparition rather than as some feature - paranormal or otherwise - of the dynamic of the group of visionaries. The counterargument is that that if that were so, how could it occur in such a controlled and organised way? None of the witnesses has demonstrated any vanishing of their voice except at the time of an apparitional event, and if the psychokinesis were emanating from the visionaries it might be surmised that it would have also manifested in those in their immediately vicinity. Moreover, the visionaries have not demonstrated any of the psychical abilities described in the preceding paragraphs when not in apparitional circumstances.

The ESP-PK hypothesis proposes that self-images of the apparition are perceivable through ESP. Most people's ideas or memories of what they look like are incomplete and inaccurate at best, being dominated by such phenomena as frontal and left-right reversed full-face images in mirrors that means that our idea or image of what it is like to be oneself is a very different thing from reality. In the Medjugorje scenario, the visionaries' perception of the apparitional image is not entirely congruent with the classical features of the ESP-PK hypothesis. However, those features are to a significant extent merely hypothetical. The fact is that what we know about apparitional experiences is comparable to what the ancient Greeks comprehended about electricity when they discovered that if you rub pieces of amber on your sleeve, they will pick up straws. In conformity with Occam's razor, the most tenable explanation is that the RSPK-type happenings at Medjugorje are externally controlled and not internally regulated.

We have here the opportunity to modify the ESP-PK hypothesis in the light of medical and scientific findings relating to Medjugorje. Let us assume that we are all endowed with dormant Super-psi faculties in a limited form. In apparitional experiences, the Super-ESP powers of the percipient are enhanced by the Super-PK powers of the apparition, and the result is the apparitional sightings. The term RSPK (recurrent spontaneous psychokinesis syndrome), when used to refer to cases involving discarnate agents, is perhaps something of a diversion as it delays the process of finding a convincing explanation for events [61]. However, application of the terms "RSPK-type activity' and 'PK-type activity" is justifiable in this context. The current ESP-PK theory of apparitions may be modified to the Super-ESP and discarnate-PK-type activity theory of apparitional events. We have to accept the fact that the Super-psi concept will continue to complicate interpretations of all the evidence that is relevant to life after death.

The observable physical events of Medjugorje may be summarised in these few words, "six visionaries talking to thin air in a silent manner for 38 years", all the rest being the private experience of the seers. The disappearance of the voices of the Marian visionaries - an entirely recognisable phenomenon - is an externally generated and controlled psychokinetic-type feature that may be termed transcendental. Most RSPK incidents may be explained as manifestations influenced by physical and psychological processes, yet there are some recently investigated cases that defy such a theory and support the survival hypothesis [62]. The events at Medjugorje may be classified as RSPK-type activities incorporating abundant visions. Witnesses reported that the visionaries were conversing with the apparition for prolonged periods in a state of silence.

The kinetic aspects of generic apparitions fit into the fabric of para-physics, but apparitions of a higher order do not. Para-physics has no coherent definition, and is a broader term even than parapsychology, but it has a more fundamental basis in physical reality [63]). The kinetic mechanism of the apparition's physical manifestation may bring the apparitional phenomenon to our scientific imagination, but that does not imply that an apparition of a higher order used it. A manifestation of a promised visible sign is awaited on the rocky hills of Medjugorje. The fulfilment of the Medjugorje predictions would be eventually recognised as confirmation of their transcendental origin, and the existence of a prediction of a visible sign with precise sequential details may be postulated as indicative of its superior logic and authenticity - it is hard to explain such manifestations as fraudulent. To adapt a quotation attributed to Charles Alexandre de Calonne [64], "The impossible takes a little longer."

Science does not prove Marian apparitions, but it does offer some indications about them. Dr Luigi Fregerio commented that science provides clues that lead towards proof [44]. Medical tests alone may not convince us that a paranormal event is taking place, but in collaboration with our existing parapsychological knowledge about apparitional phenomena they may offer pointers that lead towards proof of a genuine manifestation of a Marian apparition - or simply to its likelihood - taking place at Medjugorje. The combination of various pieces of evidence undoubtedly leads to proof. The criminal court standard is to furnish evidences beyond reasonable doubt and civil court standard is preponderance of evidences ie, evidences for outweigh the evidences against. The scientific and parapsychological evidences satisfy the second standard and support Marian apparitional manifestations at Medjugorje if not prove them. After all, studies of consciousness are mostly based on a science of court room logic and not a laboratory science [65].

\section{Conclusion}

The present author does not claim to have demonstrated 
irrefutably that Marian apparitions are taking place at Medjugorje but has found and reported evidence that makes their occurrence seem possible. I freely welcome every logical argument against the belief that these renderings are what they purport to be but placing these arguments in opposition to the evidence which I have of the genuineness of them, the affirmations outweigh the denials. As science is based on empirical observation rather than on revelation, our deductions are always subject to modification when new data accrue. The discipline of science does not enable absolute proof about anything.

Provided we trust the visionaries, the scientific observations presented in this discussion offer us the option of believing in the reality of the Marian apparitions at Medjugorje until proved otherwise. A humanly incomprehensible alternate explanation is to be recognised as a possibility even for the most authentic paranormal phenomenon and such a predicament leads us to a $99.9 \%$ conviction or $0.1 \%$ reservation for even the most convincing paranormal occurrence. But, positive theological inputs fill this void at Medjugorje.Interestingly this incomprehensibility factor is advantageous for spiritual growth as a persuading force to develop a degree of faith. It is the ants in the sugar bottle that stir up the sugar-doubts about faith prompt spiritual searching of faith and spiritual litmus testing can complement the scientific methods.

The late Professor David Fontana points out that the procedure of developing trust and faith is part of spiritual evolution [66]. Scientists are obliged to keep reservation about the unfathomable aspects of a mystical occurrence in reverence for them. Theologians have an approximate spiritual model of Marian visions, but not an intellectual model, and modern theologians are technically minded. Such a situation is an impediment in appreciating Marian apparitions for theologians who are the care takers of Mary's earthly appearances. The criterion for studying apparitions, I have proposed in this paper is a rather straight forward one and could offer an intellectual model and a tool.

Medjugorje may have the potential to be far more influential in the scientific thinking of the twenty-first century than the large Hadron collider. Figuratively, it may already be deemed something of a spiritual Hadron collider. Current theories of physical reality are inadequate for scientists to embrace the mystical and the possibility of a discarnate existence, and a new theory of physical reality needs to emerge. A unification of general relativity and quantum theory in physics may give rise to a new theory of physical reality. In order to bring mysticism into the realm of physicist's imagination, we may also have to conjecture a quantum-like dimension - a spiritual dimension. Mystical experiences of a higher order like Marian apparitions make discarnate existence promising and they confirm the existence of a richer reality; earthly sufferings become more meaningful and rewarding.

\section{Conflict of Interest}

The author declares no conflict of interest.

\section{Acknowledgements}

I am grateful to the late theologian, Fr Slavko Barbaric for the encouragements.

\section{References}

[1] Pandarakalam J. P. Are the Apparitions of Medjugorje Real? Journal of Scientific Exploration 2001; 15 (2): 229-239.

[2] Pandarakalam. J. P. Certain Parapsychological aspects of the Visionary Experiences of Medjugorje. Paranormal Review2006; 38: 14-21.

[3] Pandarakalam J. P. Medjugorje Apparitional Occurrences; A Parapsychological and Spiritual Analysis. Journal of Spiritual and Paranormal Studies 2011; 34: 100-117.

[4] Schewebel J. L. Apparitions, Healings, and Weeping Madonnas: Christianity and the Paranormal. Mahwah. N. J.: Paulist press, 2004.

[5] Soldo Mirjana. My Heart Will Triumph. page 138, Cocoa, FL32922: Catholic Shop publishing, 2016.

[6] Bartulica N. Medjugorje; Are the Seers Telling the Truth? A Psychiatrist's Viewpoint. Chicago, LL Croatian Franciscan Press, 1991.

[7] Cavar S. The first Months of the Apparitions in Medjugorje. Medjugorje: Ziral, 2000.

[8] Gelder M., Gath D., Mayou R. Oxford Textbook of Psychiatry. Oxford: Oxford Medical Publicationsm, 1989.

[9] Sims A. Symptoms in the Mind. London: Baillier Tindall, 1988.

[10] Walter GW. The Living Brain. London: Penguin, 1961.

[11] Hallson Peter (2006) A Modern Psychomanteum, Paranormal Review. April Issue 38, p 3-5.

[12] Osis K. Symposium: Apparitions, A new Model. Research in Parapsychology, p1-7 London: The Scarecrow Press, 1980.

[13] Duncan, L. and Roll, W. G. Psychic connections. New York: Delacorte, 1995.

[14] Osty, E. Supernormal Faculties in Man. London: Methuen, 1923.

[15] Roll G W. Pagenstecher's contribution to parapsychology. Journal of the American Society for Psychical Research 1967; 61: 219-240.

[16] Roll G W. Theory and Experiment in Psychical Research. New York: Amo Press, 1975.

[17] Schwartz E, R. G, Russek G, S, L. The Living Energy Universe. Charlottesville: Hampton Road Publishing Company. 1999.

[18] Stevenson I. The contribution of apparitions to the theory of survival. Journal of the American society for psychical research 1982; 76. 341-358. 
[19] Morse R D. The evidence for psychokinesis. Journal of Spirituality and Paranormal Studies 2011; 3 (34): 123.

[20] Rhine L. Mind over Matter: Psychokinesis. New York: Macmillan, 1970.

[21] Carpenter J. Projective testing on Tina Resch, October 1984. Paper presented at the Proceedings of Presented Papers: The parapsychological Association 36th Annual Convention 1993; 492-499.

[22] Roll, G. W. Some physical and psychological aspects of a series of poltergeist phenomena. Journal of the American Society for Psychical Research 1968; 62, 263-308.

[23] Roll, G. W. The Poltergeist. New York; Nelson Doubleday, 1972.

[24] Roll, G. W. Poltergeists In Wolman B. B. (Ed) Handbook of Parapsychology, New York: Van Nostrand Rein hold, 1977.

[25] Walker EH. Consciousness and Quantum theory. In White, J. (Ed.). Psychic Exploration. New York: Putnam's Sons, 1974.

[26] Owen, A. R. G. Can we explain the poltergeist? New York: Garrett, 1964.

[27] Bender, H. (1969). Presidential address: New developments in poltergeist research. Paper presented at the Proceedings of the Parapsychological Association 1969; 6: 81-102.

[28] Myers E. W. H. Human Personality and its Survival of Bodily Death. vol. 1. New York: Longmans, Green, 1903.

[29] Roll G W. The Poltergeist. New York: Paraview, 2004.

[30] Gearhart, L., \& Persinger, M. A. Geophysical variables and behaviour: XXX111. Onsets of historical and contemporary poltergeist episodes occurred with sudden increases in geomagnetic activity. Perceptual and Motor Skills 1986; 62: 463-466.

[31] Roll G W and Gerhart, L. Geomagnetic perturbations and RSPK. In Roll, W. G., Morris, R. L. \& Morris, J. (Eds). Research in Parapsychology Metuchen. N. J: Scarecrow, 1973.

[32] Persinger $\mathrm{M}$ and Cameron R. A. Are earth faults in some poltergeist-like episode? Journal of the American society for Psychical Research, 1986; 80: 49-73.

[33] Radin D. I., \& Roll, W. G. A radioactive ghost in a music hall. Procedings of the $37^{\text {th }}$ Annual Convention of the Prapsychological Association of University of Amsterdam, 1994.

[34] Roll, W. G., and Nichols A. A Haunting at an army post. Proceedings of the $42^{\text {nd }}$ Annual convention of the Parapsychological Association 1999; 253-270.

[35] Roll, W. G., and Nichols A. Psychological and electromagnetic aspects of haunts. Proceedings of the $43^{\text {rd }}$ Annual Convention of the Parapsychological Association. $2000 ; 364-378$.

[36] Persinger M. Mystical and Religious experinces as artifacts of temporal lobe function: a general hypothesis. Perceptual \& MOTOR Skills 1983; 57: 1255-1261.

[37] Persinger $M$ and Roll W. In Haunting and Poltergeist: Multidisciplinary perspectives. Jefferson, N. C: McFarland, 2001.
[38] Joines W. A wave theory of psi energy. Research in Parapsychology1975; 147-149.

[39] Wolman B. Handbook of Parapsychology, New York Van Nostrand Rein hold, 1977.

[40] Stevenson I. Are Poltergeists dead or are they living? Journal of American Society for Psychical Research 1972; 66.

[41] Auerbach L. Haunting and Poltergeists. Oakland, CA: Ronin Publishing, 2004.

[42] Laurentin R and Joyeux H. Scientific and Medical Studies on the Apparitions at Medjugorje, Dublin, Mount Salus Press, 1987.

[43] Laurentin R. Medjugorje Testament. Toronto: Ave Maria Press, 1998.

[44] Friegerio L, Mattalia G., Bianchi. L. Dossier Scientific Su Medjugorje. Marzo, Associaziono Regina della Pace, 1986.

[45] Kraljevic S. The Apparations of Our Lady at Medjugorje, Chicago: Franciscan Herald Press, 1984.

[46] Pandarakalam J. P. Understanding La Salette Apparition. Journal of Spirituality and Consciousness Studies (2015); 38: 25-35.

[47] Walsh TW. Our Lady of Fatima. New York: Macmillan, 1947.

[48] Sharkey D and Debergh J. Our Lady of Beauraing. St Meinard, Indiana: Abbey Press, 1973.

[49] Suel G and Miller O. She Went in Haste to the Mountain (Three volumes). Cleveland, Ohio: St Joseph Publications. 1981.

[50] Greene M. The voices and its Disorders. London: Pitman Media, 1980.

[51] Gallgher B. The Medjugorje Message, Number 95, January, 2011.

[52] Bubalo J. A thousand Encounters with the Blessed Virgin Mary in Medjugorje. Illinois: Friends of Medjugorje, 1987.

[53] Holt J. Nicola, Simmonds- Moore Christine, Luke David and French C. Christopher. Anomalistic Psychology. Basingstokw: Palgrave Macmillan, 2012.

[54] Braude S. Immortal Remains. New York: Rowman and Littlefield, 2003.

[55] Sudduth M. Super-Psi and the Survivalist Interpretation of Mediumship. Journal of Scientific Exploration 2009; 23: 167193.

[56] Beichler E. J. To Die For: The Physical Reality of Conscious Survival. Bloomington: Trafford Publishing, 2008.

[57] Heath Rae Pamela, Klimo John (2006) Suicide, What really happens in the Afterlife? California: North Atlantic Books.

[58] Vandersande WJ. Life After Death: Some of the Best Evidence. Colarado: Outskirts Press, 2008.

[59] Tymn M. The Articulate Dead. Lakeville MN: Glade Press, 2008.

[60] Cunningham P. The Apparition at Medjugorje: A Transpersonal Perspective. Journal of Transpersonal Psychology 2011; 43 (1) part-1: 50-76. 
[61] Broughton S. Richard (2002). Book review on Hauntings and Poltergeists: Multidisciplinary perspectives. Journal of Scientific Exploration 2002, 16 (2): 295.

[62] Houran James \& Rense Lange (2001) Hauntings and Poltergeists: Multidisciplinary perspectives. Jefferson, NC: MacFarland.

[63] Beichler E J. To Be or Not to Be! A Paraphysics for the new millennium. Journal of scientific exploration 2001; 15 (1): 3356 .
[64] Haraldsson Erlandur. In Memory of Karlis Osis. The Journal of Parapsychology 1997; 61 (3): 253-255.

[65] Tymn M. Proof Has Many Faces. The Search Light, The Academy for Spiritual and Consciousness Studies 2017; 26 (3): 15 .

[66] Fontana David. Is There an Afterlife? A Comprehensive Overview of the Evidence. London: O Books, 2005. 